\title{
Reproductive justice beyond the pill
}

\section{Donna Drucker: Contraception: a concise history. Cambridge: The MIT Press, 264pp, 2020, \$15.95 PB}

\section{Agata Ignaciuk ${ }^{1}$}

Accepted: 24 September 2021 / Published online: 20 October 2021

(c) The Author(s) 2021

In the final sentence of Contraception: A Concise History, Donna Drucker states that a "greater awareness of the past, present and future of contraception provides a framework for individual decision making and forwards understanding of the role of contraceptive technology in the making of the human world" (181). This assertion neatly summarises the book's objective, which is, over the course of the text, satisfactorily fulfilled. An accessible yet nuanced history of contraception from the late nineteenth century onward, Contraception: A Concise History also explores contemporary contraceptive technologies and ongoing projects in birth control research. Bringing together material from a range of both recent and classic histories of contraception, as well as a range of primary sources (especially with regards to barrier contraceptive methods), Drucker produces a highly readable account with a timeline structured around the introduction of the universally acknowledged game-changer in this history: the oral contraceptive pill. Circulated primarily as a therapeutic drug during the late 1950s, the pill was remarketed in the US as a contraceptive in 1960, after its manufacturer, G. D. Searle, received the necessary approval from the FDA. With the link between sex and reproduction broken, the unprecedented effectiveness of the pill became a new standard against which contraceptive products and devices, such as spermicides, barrier methods, and behavioural methods such as withdrawal and (periodic) abstinence, have been measured ever since. None of these methods have disappeared, as Drucker shows in a chapter dedicated to nonhormonal contraception after the pill, but many have undergone material and symbolic transformations, with significant international variations. For instance, in the early 1970s, the development and marketing of the intrauterine device model called the Dalkon Shield, which proved disastrously dangerous and damaging to many women who used it, was to a large extent a response to a peak in scientific and social debate about the side-effects of the pill in the United States and Europe. But Drucker's innovative contribution in Contraception: A Concise History is that she goes

Agata Ignaciuk

agataignaciuk@ugr.es

1 Department of the History of Science, University of Granada, Granada, Spain 
beyond providing essential information on the history of contraception in the Global North, and brings to the fore the theme of reproductive justice, an area of research and activism that has continued to expand over the past two decades. Drucker uses the powerful lens of reproductive justice to rethink the history of contraception. A concept developed by feminist thinkers and activists of colour, the history of which Drucker examines in detail in the fifth chapter, reproductive justice requires consideration of local and global stratifications and gendered, racialised, and classed power imbalances relating to reproduction in three key areas: "the right to have a child, the right to not have a child, and the right to parent children safely and healthily" (13). Contraception: A Concise History focuses primarily on the first of these areas, the right to have a child, but Drucker pays close attention to the many contexts in which governments, non-governmental organisations and healthcare providers have promoted contraceptive technologies without effective transparency and consent, a practice that has disproportionally affected people of colour and the Global South. As this book's conceptual backbone, the reproductive justice perspective serves not only to knit together intersecting histories of technologies but also places them firmly in relationship with individual bodies: gendered, racialised and classed. The inclusion of relevant case studies from East Central Europe, Asia and Africa illustrates these dynamics in a context that goes beyond the historiographic narrative of the Global North. In a similar vein, the concluding chapter, dedicated to current problems and challenges in the field of contraceptive technologies, raises the central issue of effective access to contraception; not only the commercial availability of products, but also the information required by both users and providers for contraceptive devices to be effective. To this end, Drucker provides the example of the specific contraceptive needs of trans people, which are often unmet due to providers' lack of familiarity with these requirements. This is one of the many instances where the author competently engages with the issue of contraceptive effectiveness and in particular the impacts of individual and social factors on this effectiveness. I particularly enjoyed the fourth chapter, in which Drucker discusses post-pill effectiveness studies of different contraceptive methods, especially early research into a number of US-branded spermicides published by William H. Masters and Virginia E. Johnson in 1963, which revealed that their effectiveness differed according to intercourse technique: "having sex in multiple positions, lengths of foreplay and intercourse, women's level of natural lubrication, the number of children the woman had previously and the use of artificial lubricants all affected contraceptive effectiveness [of spermicides in forms of foams, creams and gels]" (114). This example yet again illustrates the key historical interactions between technology and technique, and the physical and social body, that the history of contraception can so effectively unveil. To conclude, Contraception: A Concise History provides an excellent introduction to the history of contraception. The book is well-written and well organised, persuasively argued and innovative in using the reproductive justice perspective to revisit some well-known milestones in the history of contraception and to shed light on less-known ones, particularly in the history of spermicides. A helpful glossary and a rich index, together with a comprehensive further reading list increase the educational value of the book, which will be a valuable resource for students in a range of fields, including not only history, anthropology and sociology, but also public health 
and gender studies. I would also recommend it as an excellent introductory read for any scholar, journalist or policymaker who has a professional engagement with contraception or its long and interesting history.

Funding Open Access funding enabled and organized by Projekt DEAL.

Open Access This article is licensed under a Creative Commons Attribution 4.0 International License, which permits use, sharing, adaptation, distribution and reproduction in any medium or format, as long as you give appropriate credit to the original author(s) and the source, provide a link to the Creative Commons licence, and indicate if changes were made. The images or other third party material in this article are included in the article's Creative Commons licence, unless indicated otherwise in a credit line to the material. If material is not included in the article's Creative Commons licence and your intended use is not permitted by statutory regulation or exceeds the permitted use, you will need to obtain permission directly from the copyright holder. To view a copy of this licence, visit http://creativecommons.org/licen ses/by/4.0/.

Publisher's Note Springer Nature remains neutral with regard to jurisdictional claims in published maps and institutional affiliations. 